\title{
The effects of salinity on growth and survival of mangrove seedlings
}

\section{changes with age}

\section{Kodikara Arachchilage Sunanda Kodikara ${ }^{1,2^{*}}$, Loku Pullukuttige Jayatissa1, Mark Huxham ${ }^{3}$, Farid Dahdouh-Guebas ${ }^{2,4}$ and Nico Koedam ${ }^{2}$}

Received: March 16, 2017

Accepted: August 23, 2017

\begin{abstract}
Six wide-ranging mangrove species, Rhizophora apiculata, R. mucronata, Avicennia marina, A. officinalis, Bruguiera gymnorrhiza, and B. sexangula, were selected to study the growth and survival of seedlings under three contrasting salinity treatments over a 30-week period: low (3-5psu), moderate (15-17psu) and high (33-36psu). Seedlings grown under high salinity exhibited significantly lower performance $(\mathrm{p}<0.05)$ in survival rates, cumulative shoot height, mean growth rates, mean total leaf area, and mean dry weight, compared to those under low and moderate salinity regimes. The low salinity treatment provided the best conditions for initial establishment and growth of the seedlings of all species until 15-20 weeks of age. However, the same seedlings showed better performance under moderate salinity after 15-20 weeks of age (shift in optimal salinity), implying that adaptation to salt and physiological needs of mangrove seedlings varies with age. These results have practical implications of use in raising up mangrove nurse species for planting since it indicates that seedlings should get low salinity water until four to five months of age and then moderately saline water, in order to achieve maximum growth and survival.
\end{abstract}

Keywords: Avicennia, Bruguiera, early growth, mangroves, nursery, planting, Rhizophora, salinity, Sri Lanka, survival

\section{Introduction}

Mangrove forests are unique plant communities restricted to biotopes with harsh conditions i.e., intertidal areas of lagoons, estuaries and sheltered bays in tropical and sub-tropical areas worldwide (Polidoro et al. 2010; Spalding et al. 2010; Mukherjee et al. 2015). They are capable of growing under extreme environmental conditions such as high and changing salinity, frequent tidal inundation with associated sediment hypoxia, low air humidity and high temperatures as well as strong variations therein. Despite all the ecological services and economic benefits associated with mangrove ecosystems, global mangrove cover continues to decline (Bandaranayake 1998; Duke et al. 2007; Nagelkerken et al. 2008; Walters et al. 2008; Lee et al. 2014; Richards \& Friess 2016).

The main drivers for this on-going loss are that mangrove forests are converted to other land uses including urban development, industries, shrimp farms, roads and dumping sites (Dahdouh-Guebas et al. 2002; Duke et al. 2007; Polidoro et al. 2010). Therefore, mangrove conservation has become a priority and this includes widespread efforts at forest restoration. For example, the Sri Lankan government has an active programme of mangrove restoration, stimulated in particular by the 2004 Indian Ocean tsunami. The restoration programme aims at providing safeguards against natural calamities like ocean surges (Dahdouh-Guebas et

1 Department of Botany, University of Ruhuna, Wellamadama, 81000, Matara, Sri Lanka

2 Laboratory of Plant Biology and Nature Management, Ecology and Biodiversity, Faculty of Sciences and Bio-engineering Sciences, Vrije Universiteit Brussel - VUB, Pleinlaan 2, B-1050, Brussels, Belgium

3 School of Applied Sciences, Edinburgh Napier University, Sighthill Campus, Edinburgh, EH11 4BR, UK

4 Laboratory of Systems Ecology and Resource Management, Department of Organism Biology, Faculty of Sciences, Université Libre de Bruxelles ULB, F.D. Roosevelt 50, CPI 264/1, B-1050 Brussels, Belgium

* Corresponding author: sunandaruh@gmail.com 
al. 2005; Nagelkerken et al. 2008). However, these planting initiatives have often not been supported by sound scientific data. Governments, international and national NGO's and coastal communities have shown great interest in mangroverestoration activities although many attempts in Sri Lanka suffer high failure rates (Kodikara et al. 2017).

Several studies report that ignorance of the major ecological drivers of mangrove health, such as the ecological requirements for salinity, appropriate hydrology and topography and suitable species composition were the main causes for mangrove restoration failure (Elster 2000; Primavera \& Esteban 2008; Ahmad 2012; Kodikara et al. 2017). Salinity is one of the most important factors influencing the health, distribution, growth and productivity of mangroves (Ball 2002). It often shows high spatial and temporal fluctuations, driven by inputs of fresh water and sea water, inundation, ground water seepage and evaporation (Naidoo 1985; Aziz \& Khan 2001a), and has been shown to determine the survival and growth of planted mangrove seedlings in studies of mangrove restoration projects in a range of sites (Bosire et al. 2008; Kirui et al. 2008; Krauss et al. 2008; Hoppe-Speer et al. 2011).

Therefore, understanding species-specific responses to salinity is an important concern in mangrove planting projects (Ye et al. 2005; Krauss et al. 2008). Some studies suggest that the maximum growth performance of seedlings, of at least some species occur under moderately saline conditions e.g. 17.5psu (Aziz \& Khan 2001a; Jayatissa et al. 2008; Flowers \& Colmer 2015). In contrast, other studies report that water with much lower salinity increases survival, growth and productivity (e.g. Yakir \& Yechielie 1995). The salinity range that mangrove plants are able to tolerate in the field varies according to the species and it depends on the ability to maintain high water use efficiency (Reef \& Lovelock 2015). For example, Avicennia marina demonstrates extreme salt tolerance (Kirui et al. 2008), Rhizophora mucronata shows relatively high salt tolerance whilst species such as Bruguiera sexangula, Sonneratia caseolaris, and Aegiceras corniculatum show moderate or low salt tolerance (Hogarth 2007; Jayatissa et al. 2008). In addition to survival and growth, the effects of salinity on tissue water potential, physiological aspects like stomatal conductance and the role of inorganic ions in influencing mangrove seedling response to different salinity levels have all been reported (Smith \& Snedaker 1995; Aziz \& Khan 2001a; b; Reef \& Lovelock 2015). Therefore, different salt tolerance mechanisms, the levels of tolerance of different species, the effects of salinity on biomass, growth performances, water status, water uptake and physiology have all been studied. However, much remains to be discovered; for example, to the best of our knowledge age-specific shifts in optimal level of salinity for better performance of mangrove species have not been reported. Field observations provide useful indications of the optimal salinity shift of mangrove plants. However, it is difficult to confirm the optimal salinity conditions for growth in the field as the effects of salinity are confounded by many other variables. Variations in the responses of mangrove seedlings to two contrasting salinities were studied by Jayatissa et al. (2008) who found that neither taxonomy nor vivipary characteristics were good predictors of salinity tolerance in seven species (the same mangrove species were used in the current study). However, the work by Jayatissa et al. (2008) was carried out only for 14 weeks and only under two contrasting salinities: low (3-5psu) and intermediate (25-27psu). Although there are some records that seedlings use salinities ( $<15 \mathrm{psu})$ for their optimal growth (Naidoo 1985; Smith \& Snedaker 1995; Ogrady et al. 1996) there are no records for the establishment and growth, particularly of, mangrove species adapted to high salinity such as some of those used in this study, under continuous exposure to such low saline conditions. There is some evidence for that the optimal salinity for a mangrove species could vary with age, particularly during the early life stages (Ball 2002; Krauss et al. 2008).

However, to the best of our knowledge, there are no studies specifically examining how age affects responses to salinity and comparing this between different species. This can be tested properly if the salinity tolerance is studied over a longer period with a series of salinity regimes (Krauss et al. 2008). Therefore the main aim of the current work was to study how the response to salinity of mangrove species that are commonly used in planting projects in Sri Lanka changes during their early growth stage, so that seedlings may be more efficiently raised in nurseries for planting purposes.

\section{Materials and methods}

\section{Selection of species}

All brackish water body complexes including lagoons and estuaries along the coastline of Sri Lanka $(1620 \mathrm{~km})$ that have been described by Ranasinghe (2012) were surveyed between October 2012 and February 2014 in order to evaluate mangrove planting projects. During that survey, the true mangrove species which were used in planting projects were identified. Rhizophora mucronata Lamk. and $R$. apiculata BL. provided a large majority $(\sim 80 \%)$ of the total number of mangrove seedlings planted. The rest comprised propagules or seedlings of Avicennia marina (Forsk.) Vierh., A. officinalis L., Bruguiera gymnorrhiza (L.) Lamk., and B. sexangula (Lour.) Poir. Many of the seedlings planted were nursery-maintained. Therefore, these six mangrove species were selected for the present study.

\section{Experimental design}

Mature propagules (Bruguiera gymnorrhiza, B. sexangula, Rhizophora apiculata, $R$. mucronata) and cryptoviviparous 
fruits i.e., the fruits in which the embryo grows to break through the seed coat but not the fruit wall before dropping to the ground (Avicennia marina, A. officinalis) were collected from natural mangrove sites and used as planting materials. A sandy soil was prepared by mixing sieved loam soil with sand and organic matter (degraded mangrove litter) in 1:1:1 (v/v) proportions. Collected propagules were planted in plastic pots ( $5 \mathrm{~cm}$ diameter and $15 \mathrm{~cm}$ height) filled with the prepared soil mixture and kept in a nursery irrigated with fresh water until the first two leaves unfurled. Seedlings with the first two leaves unfurled during the same short (i.e., few days) period were selected for the experiment assuming that they had the same vigour. A total of 27 seedlings from each species, all of similar size, were transferred individually to larger polyethylene bags ( $15 \mathrm{~cm}$ diameter and $40 \mathrm{~cm}$ height) filled with the same soil mixture.

The naming of the three salinity treatments as low, moderate, and high in this work, was based on the naturally occurring salinity range in lagoons and estuaries in Sri Lanka; salinities higher than 40psu in Sri Lankan lagoons or estuaries, even in drought periods, are very rare (pers. obs.). Seawater has an average of 36psu (Naidoo 1985). Three salinity treatments were used: low salinity (i.e., 3-5psu), moderate salinity (i.e., 15-17psu) and high salinity (i.e., 33$36 \mathrm{psu}$ ). Water with these salinities was prepared separately by mixing sea water and aged tap water i.e., water kept in open containers for a few days before use, to remove excess chlorine and stored in separate tanks to use for irrigating pots with mangrove seedlings. Pots with seedlings were placed individually (i.e., one per tray) on $7 \mathrm{~cm}$ deep plastic trays and distributed on benches set outside (hence exposed to ambient temperature and wind but protected from rainfall by a glazed roof) according to a completely randomized design. Each pot was irrigated twice a day by the water with the salinity assigned to each pot. Water which drained from pots and accumulated in trays was transferred to the original tanks. Based on the results of preliminary work, the salinity of the water in the tanks was checked once every three days using a hand refractometer (ATAGO S/Mill-E, Japan) and adjusted when necessary. Commercially available fertilizer was also applied once a month by providing the same amount per pot (Adapted from Jayatissa et al. 2008; Dissanayake et al. 2014). Average light condition in the greenhouse was 49400.5 (SD \pm 780.3 ) Lux between $11.45-14.30 \mathrm{hrs}$ ).

\section{Data collection}

The number of surviving mangrove seedlings of each mangrove species (from an initial number of 81 seedlings per species) was counted once a week. The shoot height from the tip of each seedling to the soil, for crypto-viviparous species, and from the tip of each seedling to the top of the hypocotyl (propagule part), for viviparous seedlings, was measured once every fortnight. All branch lengths were also measured and added to the height of the main axis and the total value was considered as the cumulative shoot height. The number of leaves in each seedling was also recorded once a week. All survived seedlings were harvested after 30 weeks of growth as this is a critical early life stage period between seedling and sapling stage (Krauss et al. 2008). Plants were removed from the plastic pots and the soil was carefully washed by immersing in water to get the root system as intact as possible. Cleaned plants were blotted dry and were separated into roots, hypocotyls, stems and leaves. Excluding hypocotyls, the fresh weights of the other three parts of each plant were measured and total leaf area per plant was quantified manually using millimeter graph paper (outline of each leaf was drawn with a pencil, after spreading over a millimeter graph paper and the area covered, was taken as the leaf area) Then all parts were oven-dried at $80^{\circ} \mathrm{C}$ for dry weight. The difference between fresh and dry weight of individual plants was taken as the water content and percentage water content was calculated as follows:

$$
\text { Percentage water content }=\frac{(\text { Fresh weight }- \text { dry weight })}{\text { Fresh weight }} \times 100
$$

Ultimately cumulative shoot height, mean dry weight, mean total leaf area, and mean percentage water content of seedlings under different salinity regimes were compared.

\section{Data analysis}

The four variables mean shoot height (height at the end of the study period), mean dry weight, mean total leaf area and mean percentage water content were compared among the fixed factors species and salinity levels using two-way ANOVA. Residuals were examined to determine if transformations were required. Where there were significant interactions between these two factors each was examined separately and differences between levels determined using Tukey tests. Data were plotted using $95 \%$ confidence intervals, to allow visual inference of significant differences for all variables examined.

\section{Results}

\section{Rates of survival}

Rates of survival of mangrove seedlings in low salinity were higher than those in the moderate and high salinity 
treatments (Fig. 1). At the end of the study period, low and moderate salinity regimes showed the higher mean rates of survival (ranging between $80-97 \%$ ). The lowest rates of survival were observed in the high salinity treatment. The shapes of the survivorship curves differed qualitatively between the three treatments. Survival continued to decline at roughly constant rates for most species in the high salinity treatment. In contrast, survival in the low and moderate salinity treatments showed initial small drops followed by relative constancy for all species, except the two Avicennia species.

\section{Growth performances}

The shoot heights of all six species in all three salinities showed little increase until the $5^{\text {th }}$ week, but increases after the $5^{\text {th }}$ week were clearly visible (Fig. 2). The shoot heights of seedlings of all the species grown under high salinity increased at a lower rate throughout the study period whilst those under moderate salinity and low salinity increased at higher rates. The shoot heights of seedlings of the two Rhizophora spp., and of B. gymnorrhiza, grown under moderate salinity were higher $(\mathrm{p}<0.05)$ than those of the low salinity treatment at the end. The growth rate (increment of the shoot height per fortnight) varied depending on the species (Fig. 3). Generally, the highest and lowest growth rates were observed in Avicennia spp. and Bruguiera spp. respectively whilst the growth rates of Rhizophora spp. were in-between. Nevertheless, some similarities in the variations of the growth rate of all six species were observed i.e., in each of the six species, the mean growth rate of individuals grown under the high salinity regime remained lowest throughout the study period as compared to that of the individuals grown under moderate and low salinity treatments. However, at the middle or in the second half of the experimental period, a change in the pattern of variation of the growth rates of all six species was noticed. The growth rates under the moderate salinity treatment began to exceed those found in the low salinity treatment during the $15^{\text {th }}$ to $20^{\text {th }}$ week (this phenomenon is referred to here as the "shift in optimal salinity" for better performance). Before the shift in optimal salinity occurred, the mean growth rates of all six mangrove species grown under the low salinity treatment was higher compared to that of plants grown under the moderate salinity treatment. However, after the shift in optimal salinity there was significantly faster growth in moderate salinities for all species other than B. gymnorrhiza. Growth rates of the saplings grown in low salinity regime showed a decreasing trend at the end of the study period.

Mean dry weights (total biomass) of saplings as well as the mean total leaf area of 30 weeks old saplings of each of the six species grown in the high salinity treatment were lower $(p<0.001)$ as opposed to those grown in the other two treatments (Tab. 1). The mean dry weights of the saplings of all six species grown in the high salinity treatment were about half of those at the low and moderate salinity regimes. Moreover, there were no significant differences of mean dry weight and mean total leaf area between low and moderate salinity regimes (Tabs. 1, 2). The mean percentage water content in saplings of each of the species grown in the low salinity condition was higher than that of saplings grown in other two salinity regimes, except in A. officinalis and R. mucronata (Tab. 3).

\section{Discussion}

The current study considered responses of mangrove seedlings under low, moderate and high salinity conditions over the long period of 30 weeks (about seven months) because of the need to reveal slowly developing responses of mangrove seedlings (Ball et al. 1997). The observed reduction of growth performances i.e., cumulative shoot height, mean dry weight, and mean total leaf area with lower level of survival of mangrove seedlings grown under the high salinity regime in this experiment is consistent with other studies (Aziz \& Khan 2001a; Munns 2005; Parida \& Das 2005; Naidoo 2006; Reef \& Lovelock 2015). Further, the maximum growth at moderate salinity is also consistent with many other studies which have demonstrated that optimal growth rates can occur at concentrations ranging from 5 to 75 \% seawater (Smith \& Snedaker 1995; Aziz \& Khan 2001a; Jayatissa et al. 2008; Flowers \& Colmer 2015). Based on such studies, many mangrove ecologists and planting practitioners recommend moderate salinity conditions to obtain mangrove seedlings with optimum growth and high vigour in plant nurseries as well as in planting areas. But here we argue that such optimal salinity shift is age-specific and higher salinity at the very young seedling stage (1-2 months), even if moderate, might cause salt stress.

The first eight weeks of growth are crucial in determining future survival and vigour (Krauss et al. 2008). In the current experiment the highest survival rate and the optimum growth were observed in the low saline treatment during this period. Therefore, it is evident that low saline conditions are ideal for the initial establishment of mangrove seedlings with higher growth. However, the situation changed after $15-20^{\text {th }}$ weeks, with highest growth rates subsequently recorded under the moderately saline treatment in all six mangrove species studied. This situation remained until the end of the experiment, implying that the salinity most favourable for the optimum growth of mangrove seedlings changes from low to moderate after 4-5 months of age. By the end of the experiment the mean weights of A. marina seedlings grown at moderate salinity were greater than those grown at low salinity and the growth trajectories suggest that other species would have shown similar differences given further time. 


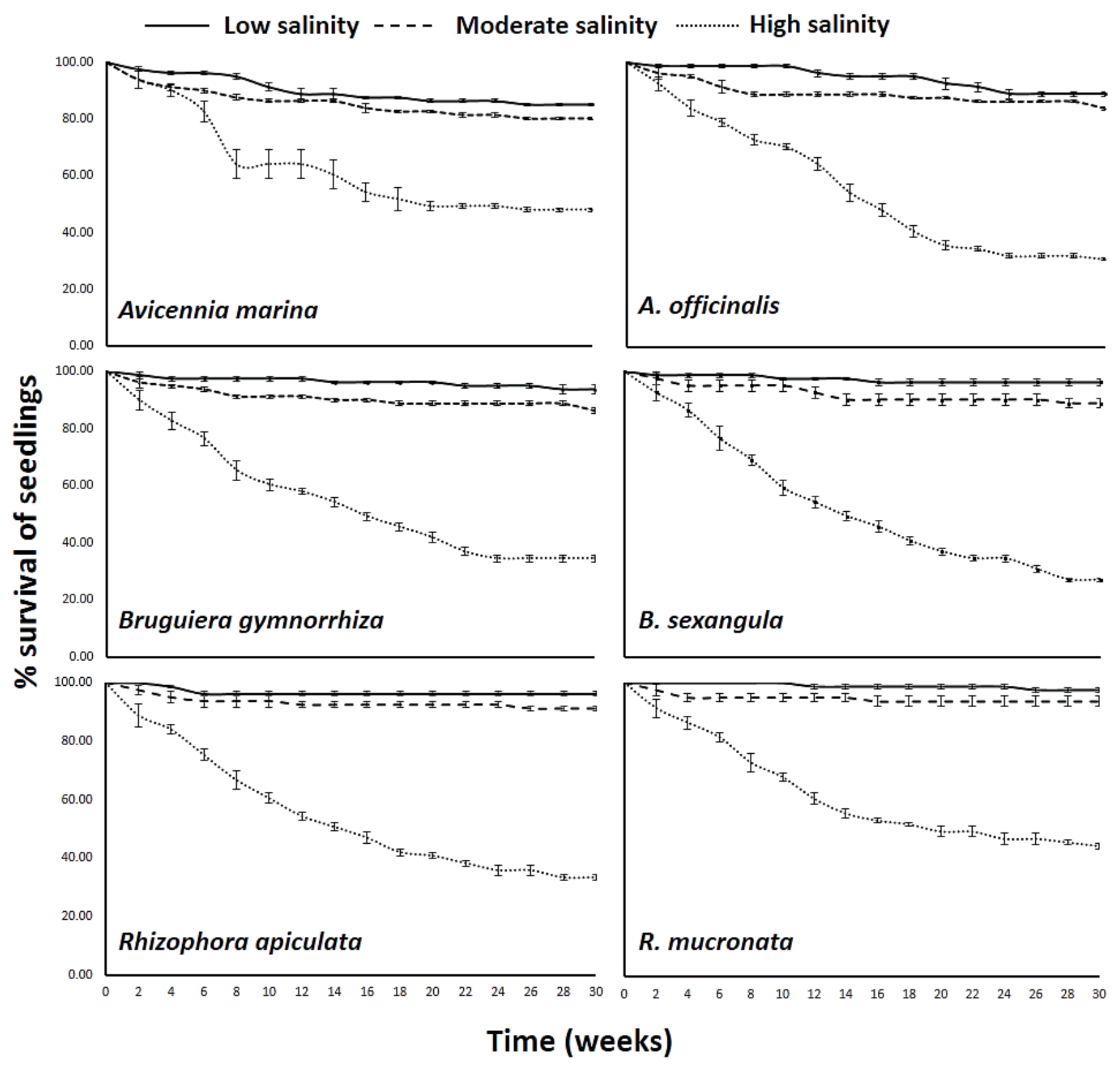

Figure 1. Mean ( $\pm 95 \%$ C.I.) percentage of survival against age of seedlings of six different mangrove species under different salinity regimes.

Higher leaf chlorophyll content under moderate saline conditions (avg. 96.8 $\pm 6.6 \mathrm{CCI}$ ) as compared to low saline conditions (avg. 70.1 \pm 4.2 CCI) (KAS Kodikara unpubl. res.) may be the reason for the greater biomass accumulation in the moderate salinity treatment despite the similar total leaf area observed under low and moderate salinities. This changing response to salinity is termed 'the shift in optimal salinity for better performance' in this paper; the experiment was repeated two more times for confirmation and the same results (KAS Kodikara unpubl. res.) were observed in the two consecutive experiments.

These results support work suggesting that salt is an essential requirement for the growth of some mangrove species (Downton 1982; Clough 1984). Therefore, it is proposed that after about 4-5 months of initial establishment, seedlings need comparatively higher amounts of salt to gain optimum growth and to maintain optimum metabolic activities. More specifically, moderate salinity may facilitate water uptake to keep optimum water status inside plants. This is further supported by the fact that the growth rate of the seedlings of the six mangrove species under the low salinity regime showed a decreasing trend after the $20^{\text {th }}$ week of age.

The exact mechanism determining the role of salt ions at this maturing stage is unknown. However, very high salinities are known to cause severe stress and stunted 


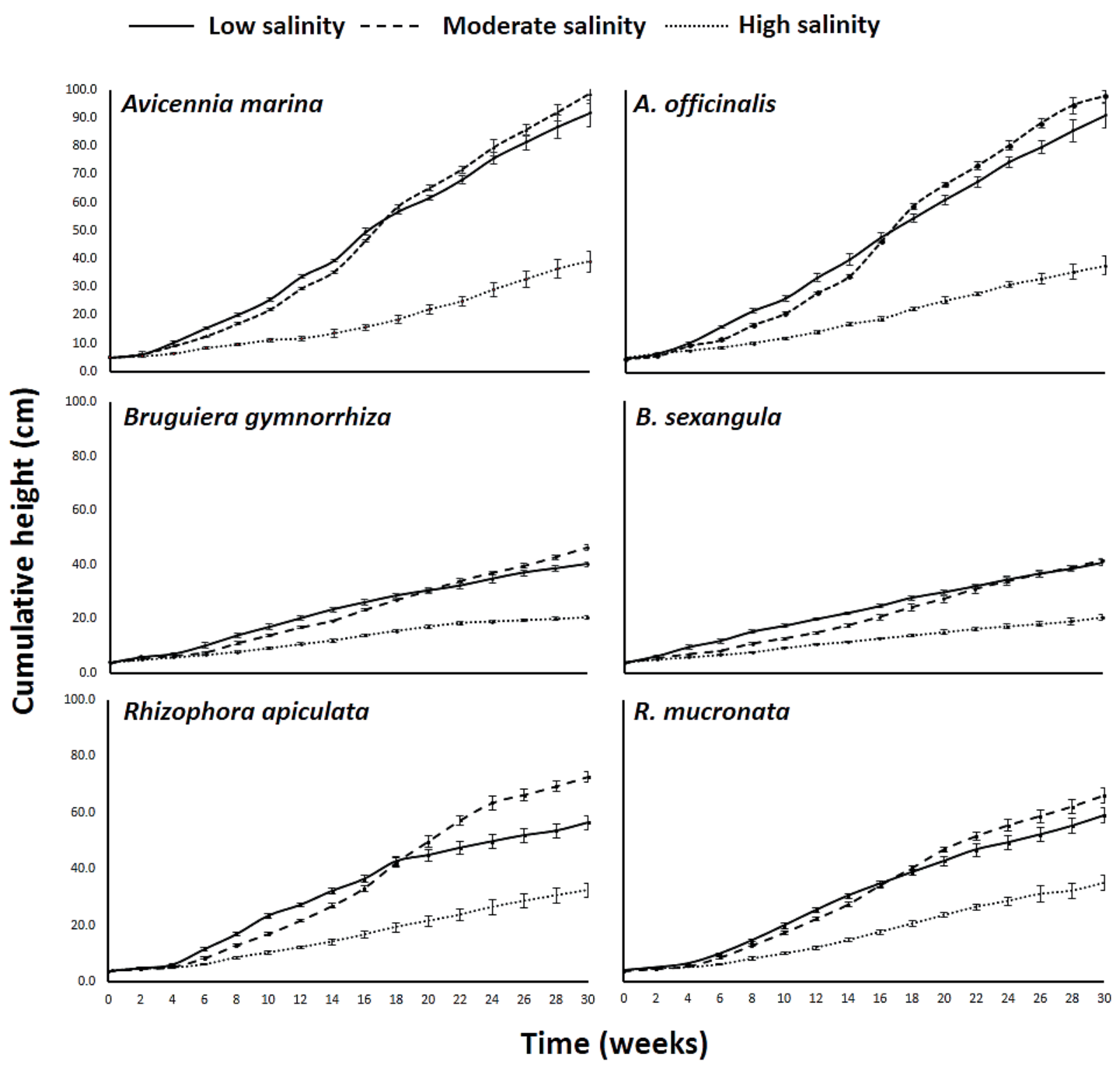

Figure 2. Mean ( $\pm 95 \%$ C.I.) cumulative shoot height against age of seedlings of six different mangrove species under different salinity regimes over time of development.

growth (Zhu 2002; Dahdouh-Guebas et al. 2004). High salinity in casu high $\mathrm{NaCl}$ concentration is often considered as a stress factor, even for mangrove plants (Ball 2002; Zhu 2002). Our results also showed that the total leaf area, which is known to be the most sensitive outward indicator of any stress (Wang \& Nil 2000), and total dry weight of mangrove seedlings were significantly lower in the high salinity treatment. The stunting of seedlings observed in this study could be due to reduced transpiration rates and photosynthesis of mangrove seedlings in high salinity conditions (Parida \& Das 2005). Hence, it seems plausible that moderate salinity could be the optimum at this maturing stage. Different salt tolerance mechanisms, such as salt exclusion, salt excretion, salt accumulation, and osmoregulation exist in mangrove plants (Tomlinson
1986). The differences found in these mechanisms, are probably be linked with shift in optimal level of salinity with age. However, it still needs some future research for better comprehension.

Previous work has suggested that salinity tolerance varies with age or growth stage of seedlings (Hutchings \& Saenger 1987; Krauss et al. 2008). This inference is supported by a study of the restoration of hypersaline areas, in which transplanted seedlings older than five months survived under conditions that prevented the establishment of wild plants (Kirui et al. 2008). Hence the present work supports field observations that seedlings beyond the critical age of early vulnerability to salt may be used successfully in restoring salinized areas. However, no previous studies have demonstrated this unequivocally. Although several 


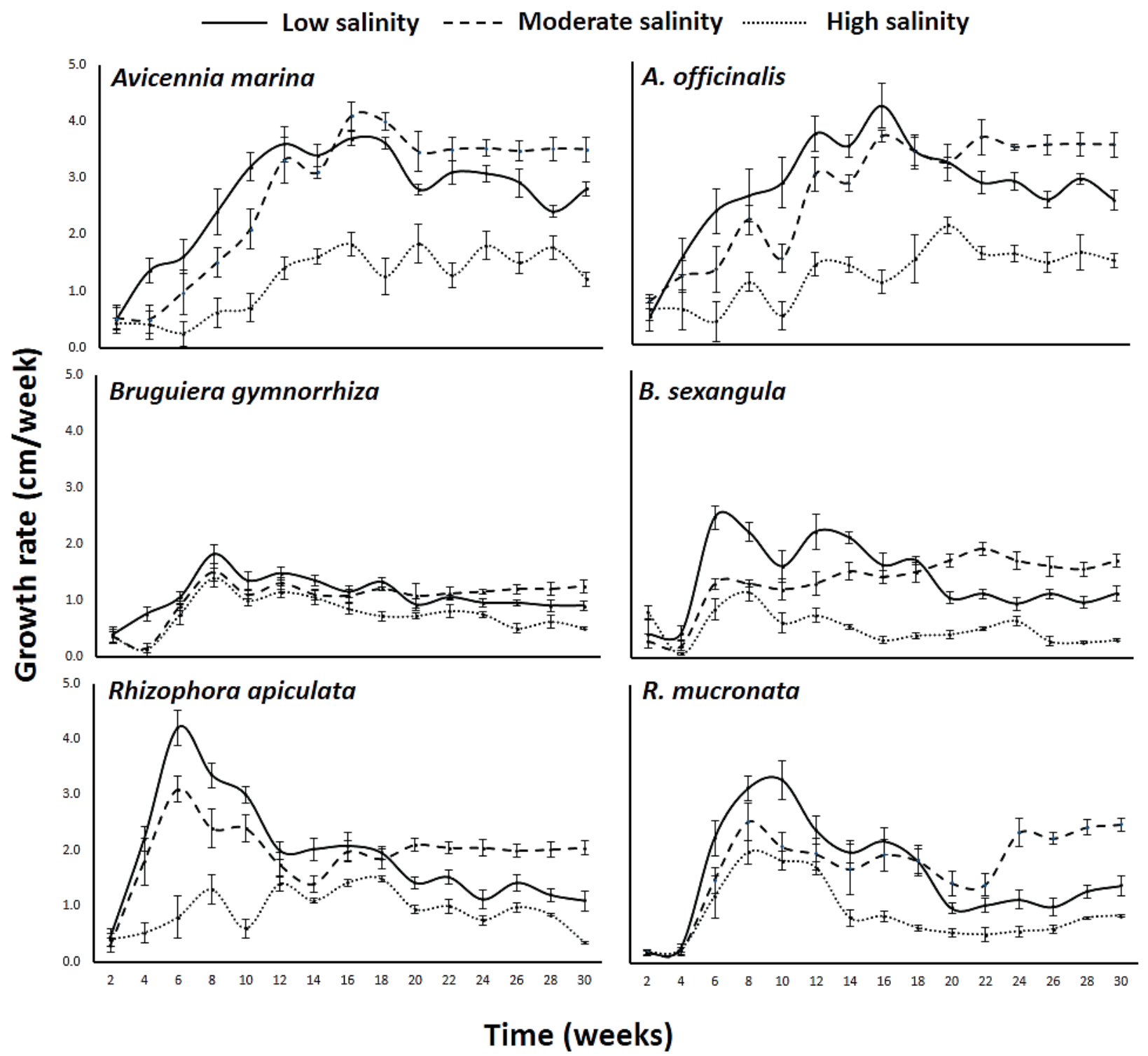

Figure 3. Mean ( $\pm 95 \%$ C.I.) growth rate or weekly increment of the shoot height of mangrove species grown in a greenhouse under different salinity regimes, low moderate and high saline regimes.

studies have been carried out on the impacts of salinity on the early growth performance of mangroves, this shift in the optimal salinity from low to moderate with the age of seedlings has not been previously described, either due to the inadequate length of the experiment (Jayatissa et al. 2008) or due to a lack of attention to the differences of the growth rate (Aziz \& Khan 2001a).

The field distributions of these species in Sri Lanka do broadly reflect different salinity tolerance; for example, the highest diversity of mangroves in Sri Lanka are reported from the lagoons and estuaries in the intermediate zone, (such as Rekawa and Kahandamodara lagoons in the southern coast and Pambala in the western coast) where the soil salinity is intermediate compared to salinities in the wet or dry zones (Jayatissa et al. 2002). In addition to the salinity shift scenario, several other aspects of relevance to restoration work have also been revealed by this study. The mean percentage water content of plants grown under the low saline conditions was significantly higher than those grown in high and moderate saline conditions, implying mangroves tend to store more water under low saline conditions (Lambs et al. 2008; Wei et al. 2013). The cause of enhanced water absorption could be due to low osmotic potential under hypersaline conditions (Parida \& Das 2005). Moreover, A. officinalis and R. mucronata did not show significant differences in water content between low and high salinities. It may be assumed that $R$. mucronata behaves differently, because it is one of the most salt tolerant species among the studied species (Jayatissa et al. 2008) although its performance under highly stressed 
Table 1. Mean dry weight ( $\mathrm{g}$ ) of seedlings of six mangrove species grown under three different salinity regimes after 30 weeks. One-way ANOVA results for factor 'species', $\mathrm{F}=0.82_{5,146}, \mathrm{P}=0.53$, 'salinity', $\mathrm{F}=429_{2,149} \mathrm{P}<0.001$. Values within each column with different superscripts are significantly different at $\mathrm{p}<0.05$

\begin{tabular}{|c|c|c|c|c|c|c|}
\hline \multirow{2}{*}{ Salinity regime } & \multicolumn{6}{|c|}{ Mean dry weight ( $\mathrm{g}$ ) of different mangrove species } \\
\hline & A. marina & A. officinalis & B. gymnorrhiza & B. sexangula & R. apiculata & R.mucronata \\
\hline Low & $25.8 \pm 3.8^{a}$ & $27.6 \pm 5.0^{\mathrm{a}}$ & $30.4 \pm 4.8^{\text {a }}$ & $28.1 \pm 3.5^{\mathrm{a}}$ & $28.8 \pm 2.3^{a}$ & $31.6 \pm 2.7^{a}$ \\
\hline Medium & $30.3 \pm 3.0^{b}$ & $25.3 \pm 2.9^{a}$ & $31.5 \pm 4.2^{\mathrm{a}}$ & $25.0 \pm 3.9^{a}$ & $30.3 \pm 2.0^{\mathrm{a}}$ & $31.4 \pm 3.1^{\mathrm{a}}$ \\
\hline High & $10.5 \pm 2.7^{c}$ & $9.6 \pm 1.7^{b}$ & $9.8 \pm 2.5^{b}$ & $5.7 \pm 2.5^{b}$ & $11.0 \pm 1.6^{b}$ & $10.7 \pm 1.7^{b}$ \\
\hline
\end{tabular}

Table 2. Mean total leaf area $\left(\mathrm{cm}^{2}\right)$ of seedlings of six mangrove species grown under three different salinity regimes after 30 weeks. One-way ANOVA results for factor 'species', F= 22.4 ${ }_{5,151}, \mathrm{P}<0.001$; factor 'salinity', $\mathrm{F}=6_{2.7}{ }_{2,151}, \mathrm{P}<0.001$. Values within each column with different superscripts are significantly different at $\mathrm{p}<0.05$.

\begin{tabular}{|c|c|c|c|c|c|c|}
\hline \multirow{2}{*}{ Salinity regime } & \multicolumn{6}{|c|}{ Total leaf area $\left(\mathrm{cm}^{2}\right)$ of different mangrove species } \\
\hline & A. marina & A. officinalis & B. gymnorrhiza & B. sexangula & R. apiculata & R.mucronata \\
\hline Low & $104.6 \pm 9.0^{a}$ & $101.8 \pm 8.6^{\mathrm{a}}$ & $140.0 \pm 9.6^{\mathrm{a}}$ & $201.6 \pm 11.7^{\mathrm{a}}$ & $227.8 \pm 5.3^{\mathrm{a}}$ & $212.3 \pm 8.7^{a}$ \\
\hline Medium & $107.7 \pm 5.5^{\mathrm{a}}$ & $101.1 \pm 5.6^{\text {a }}$ & $130.8 \pm 9.0^{a}$ & $201.6 \pm 7.7^{\text {a }}$ & $258.4 \pm 8.5^{b}$ & $224.6 \pm 11.0^{\mathrm{a}}$ \\
\hline High & $45.3 \pm 6.7^{b}$ & $46.8 \pm 5.1^{b}$ & $54.6 \pm 12.7^{b}$ & $61.6 \pm 15.0^{b}$ & $89.1 \pm 7.9^{c}$ & $116.8 \pm 19.4^{b}$ \\
\hline
\end{tabular}

Table 3. Mean percentage water content (\%) of seedlings of six mangrove species grown under three different salinity regimes after 30 weeks. Oneway ANOVA results for factor 'species', $\mathrm{F}=13.24_{5,151}, \mathrm{P}<0.001$; factor 'salinity', $\mathrm{F}=43.3_{2,151}, \mathrm{P}<0.001$. Values within each column with different superscripts are significantly different at $\mathrm{p}<0.05$.

\begin{tabular}{c|c|c|c|c|c|c|c|}
\multirow{2}{*}{ Salinity regime } & \multicolumn{6}{|c|}{ Percentage water content (\%) of different mangrove species } \\
\cline { 2 - 8 } & A. marina & A. officinalis & B. gymnorrhiza & B. sexangula & R. apiculata & R.mucronata \\
\hline Low & $77.1 \pm 3.5^{\mathrm{a}}$ & $79.0^{\mathrm{a}} \pm 4.7^{\mathrm{a}}$ & $82.6^{\mathrm{a}} \pm 2.3^{\mathrm{a}}$ & $78.9 \pm 2.7^{\mathrm{a}}$ & $77.0^{\mathrm{a}} \pm 4.3^{\mathrm{a}}$ & $71.2^{\mathrm{a}} \pm 3.0^{\mathrm{a}}$ \\
\hline Medium & $60.7 \pm 5.6^{\mathrm{b}}$ & $65.9 \pm 3.9^{\mathrm{b}}$ & $67.4 \pm 3.9^{\mathrm{b}}$ & $75.3^{\mathrm{b}} \pm 1.0^{\mathrm{b}}$ & $61.9^{\mathrm{b}} \pm 5.9^{\mathrm{b}}$ & $62.5^{\mathrm{b}} \pm 4.4^{\mathrm{b}}$ \\
\hline High & $63.2 \pm 4.7^{\mathrm{b}}$ & $76.5^{\mathrm{b}} \pm 2.0^{\mathrm{a}}$ & $71.9 \pm 5.0^{\mathrm{b}}$ & $76.0^{\mathrm{b}} \pm 1.7^{\mathrm{b}}$ & $68.5^{\mathrm{b}} \pm 2.1^{\mathrm{c}}$ & $70.3^{\mathrm{c}} \pm 3.4^{\mathrm{a}}$ \\
\hline
\end{tabular}

conditions in Sri Lanka is rather poor in comparison to competing highly salt tolerant species such as A. marina (LP Jayatissa unpubl. res.) . However, the behaviour of $A$. officinalis recorded here suggests that salt physiology in this species remains poorly understood.

When considering the growth performances and rate of survival, $R$. mucronata showed the highest growth performances with the highest survival rate under all salinity conditions. These performances could have been the major reason to mostly select $R$. mucronata for mangrove planting in Sri Lanka (Kodikara et al. 2017). Therefore, it is concluded that low saline conditions (3-5psu) are more suitable for initial establishment and higher survival rate of mangrove seedlings. However, the studied mangrove species tend to use moderate saline conditions (13-15psu) after the age of $\sim 5$ months. This suggests that salt requirements vary depending on the age of the mangrove seedlings and a comparatively higher concentration of salts is required after about five months of their establishment. High saline conditions (above 30psu) cause poor survival rate and stunted growth for all species.

During mangrove planting using nurseries, seedlings are normally transplanted during the rainy season, when the salinity is low, with the expectation that mangrove seedlings would have higher survival rate. Based on the rate of survival, growth performances and water conservation strategy, the genus Rhizophora shows a wide range of adaptive features hence it is suggested that Rhizophora is better used in mangrove planting under moderate conditions (although other genera, such as Avicennia, may be used as 'nurse species' under extreme salinity conditions; Huxham et al. 2010). This study addresses the key point that mangrove seedlings commonly raised and maintained in nurseries are usually irrigated with fresh or brackish water depending on availability, without paying attention to the salinity of water, and seedlings of a few months age are transferred to the field which could result in early seedling mortality. Therefore it may be advised to irrigate nursery plants with low saline water until about 4 to 5 months and then with moderately saline water which could ultimately improve mangrove planting. In the same way, the ideal season to transfer nursery plants to the field should be decided based on the age of nursery plants. If mangrove propagules are directly used for planting, which is commonly observed in mangrove rehabilitation programs, this should be done just before the rainy season since low saline conditions are preferred during initial establishment. Planting seedlings may mitigate the need to coincide with the rainy season, given the changing response to salinity recorded here; a good prior understanding of the seasonal salinity fluctuations in any given planting sites is recommended to allow careful matching of seedling physiology with field conditions. 


\section{Acknowledgements}

This work described in this paper was supported by the VLIR-UOS-funded "Green Dyke project" (Flemish Interuniversity Council - University Development Cooperation) and University Grant Commission, Sri Lanka (UGC/DRIC/PG/2014AUG/RUH/02). We would also like to thank Dr. M.P. Kumara for his assistance in this study.

\section{References}

Ahmad IU. 2012. Status of mangrove plantations in the living delta: an overview of the coastal afforestation experience of Bangladesh. In: Macintosh DJ, Mahindapala R, Markopoulos M. (eds.) Sharing lessons on mangrove restoration. Mamallapuram, Proceedings and a Call for Action from an MFF Regional Colloquium. p. 81-93.

Aziz I, Khan MA. 2001a. Effect of seawater on the growth, ion content and water potential of Rhizophora mucronata Lam. Journal of Plant Research 114: 369-373.

Aziz I, Khan MA. 2001b. Experimental assessment of salinity tolerance of Ceriops tagal seedlings and saplings from the Indus delta, Pakistan. Aquatic Botany 70: 259-268.

Ball MC. 2002. Interactive effects of salinity and irradiance on growth: implications for mangrove forest structure along salinity gradients. Trees - Structure and Function 16: 126-139.

Ball MC, Cochrane MJ, Rawson HM. 1997. Growth and water use of the mangroves Rhizophora apiculata and R. stylosa in response to salinity and humidity under ambient and elevated concentrations of atmospheric CO2. Plant Cell and Environment 20: 1158-1166.

Bandaranayake WM. 1998. Traditional and medicinal uses of mangroves. Mangroves and Salt Marshes 2: 133-148.

Bosire JO, Dahdouh-Guebas F, Walton M, et al. 2008. Functionality of restored mangroves: A review. Aquatic Botany 89: 251-259.

Clough BF. 1984. Growth and salt balance of the mangroves Aviennia marina (Forsk.) Vierh. and Rhizophora stylosa Griff, in relation to salinity. Australian Journal of Plant Physiology 11: 419-430.

Dahdouh-Guebas F, Bondt R, Abeysinghe PD, et al. 2004. Comparative study of the disjunct zonation pattern of the grey mangrove Avicennia marina (Forsk) Vierh.in GaziBay (Kenya). Bulletin of Marine Science 74: 237-252.

Dahdouh-Guebas F, Jayatissa LP, Di Nitto D, Bosire J, Lo Seen D, Koedam N. 2005. How effective were mangrove as a defence against recent Tsunami? Current Biology 15: 443-447.

Dahdouh-Guebas F, Zetterstro T, Ronnba P, Troell CK, Wickramasinghe A, Koedam N. 2002. Recent changes in land-use in the Pambala-Chilaw lagoon complex (Sri Lanka) investigated using remote sensing and GIS: conservation of mangroves vs. development of shrimp farming. Environment, Development and Sustainability 4: 185-200.

Dissanayake NP, Madarasinghe SK, Kodikara KAS, et al. 2014. Preliminary study on the propagule dependency of Rhizophora seedlings. Journal of Department of Wildlife Conservation 2: 141-151.

Downton WJS. 1982. Growth and osmotic relations of the mangrove Avicennia marina as influenced by salinity. Australian Journal of Plant Physiology 9: 519-528.

Duke NC, Meynecke JO, Dittmann S, et al. 2007. A world without mangroves? Science 317: 1-42.

Elster C. 2000. Reasons for reforestation success and failure with three mangrove species in Colombia. Forest Ecology and Management 131: 201-214.

Flowers JT, Colmer TD. 2015. Plant salt tolerance: adaptations in halophytes. Annals of Botany 115: 327-331.

Hogarth PJ. 2007. The Biology of Mangroves and Seagrasses. Oxford, Oxford University Press.

Hoppe-Speer SCL, Adams JB, Rajkaran A, Bailey D. 2011. The response of the red mangrove Rhizophora mucronata Lam. to salinity and inundation in South Africa. Aquatic Botany 95: 71-76.
Hutchings P, Saenger P. 1987. Ecology of mangroves. St Lucia, University of Queensland Press.

Huxham M, Kumara MP, Jayatissa LP, et al. 2010. Intra- and interspecific facilitation in mangroves may increase resilience to climate change threats. Philosophical Transactions of the Royal Society B 365: 21272135.

Jayatissa LP, Dahdouh-Guebas F, Koedam N. 2002. A review of the floral composition and distribution of mangroves in Sri Lanka. Botanical Journal of the Linnean Society 138: 29-43.

Jayatissa LP, Wickramasinghe WAADL, Dahdouh-Guebas F, Huxham M. 2008. Interspecific variation in response of mangrove seedlings to two contrasting salinities. International Review of Hydrobiology 93: 700-710.

Kirui BYK, Huxham M, Kairo J, Skov M. 2008. Influence of species richness and environmental context on early survival of replanted mangroves at Gazi bay, Kenya. Hydrobiologia 603: 171-181.

Kodikara KAS, Mukherjee N, Jayatissa LP, Dahdouh-Guebas F, Koedam N. 2017. Have mangrove restoration projects worked? An in-depth study in Sri Lanka. Restoration Ecology (in press). DOI: 10.1111/rec.12492

Krauss KW, Lovelock CE, McKee KL, Lopez-Hoffman L, Ewe SML, Sousa WP. 2008. Environmental drivers in mangrove establishment and early development: A review. Aquatic Botany 89: 105-127.

Lambs L, Muller E, Fromard F. 2008. Mangrove trees growing in a very saline condition but not using seawater. Rapid Communications in Mass Spectrometry 22: 2835-2843.

Lee SY, Primavera JH, Dahdouh-Guebas F, et al. 2014. Ecological role and services of tropical mangrove ecosystems: A reassessment. Global Ecology and Biogeography 23: 726-743.

Mukherjee N, Dahdouh-Guebas F, Koedam N, Shanker K. 2015. An interdisciplinary framework to evaluate bioshield plantations: Insights from peninsular India. Acta Oecologica 63: 91-100.

Munns R. 2005. Comparative physiology of salt and water stress. Plant Cell Environment 25: 239-250.

Nagelkerken I, Blaber S, Bouillon S, et al. 2008. The habitat function of mangrove for terrestrial and marine fauna: a review. Aquatic Botany 89: $155-185$

Naidoo G. 1985. Effects of water logging and salinity on plant-water relations and on the accumulation of solutes in three mangrove species. Aquatic Botany 22: 133-143.

Naidoo G. 2006. Factors contributing to dwarfing in the mangrove Avicennia marina. Annals of Botany 97: 1095-1101.

Ogrady AP, Mcguiness KA, Eamus D. 1996. The abundance and growth of Avicennia marina and Rhizophora stylosa in the low shore zone of Darwin Harbour, Northern Territory. Australian Journal of Ecology 21: $272-279$

Parida AK, Das AB. 2005. Salt tolerance and salinity effects on plants: a review. Ecotoxicology and Environmental Safety 60: 324-349.

Polidoro BA, Carpenter KE, Collins L, et al. 2010. The loss of species: Mangrove extinction risk and geographic areas of global concern. PLoS One 5: e10095. https://doi.org/10.1371/journal.pone.0010095

Primavera JH, Esteban JMA. 2008. A review of mangrove rehabilitation in the Philippines: successes, failures and future prospects. Wetlands Ecology and Management 16: 173-253.

Ranasinghe TS. 2012. Mangrove restoration efforts in Sri Lanka. In: Macintosh DJ, Mahindapala R, Markopoulos M. (eds.) Mamallapuram, Sharing lessons on mangrove restoration, proceedings and a call for action from an MFF Regional Colloquium. p. 75-81.

Reef R, Lovelock CE. 2015. Regulation of water balance in mangroves. Annals of Botany 115: 385-395.

Richards DR, Friess DA. 2016. Rates and drivers of mangrove deforestation in Southeast Asia, 2000-2012. Proceedings of the National Academy of Sciences 113: 344-349.

Smith SM, Snedaker SC. 1995. Salinity responses in two populations of viviparous Rhizophora mangle L. seedlings. Biotropica 27: 435-440.

Spalding MD, Kainuma M, Collins L. 2010. World atlas of mangroves. London, Earthscan.

Tomlinson PB. 1986. The botany of mangroves. London, Cambridge University Press. 


\section{Kodikara Arachchilage Sunanda Kodikara, Loku Pullukuttige Jayatissa, Mark Huxham, Farid Dahdouh-Guebas and Nico Koedam}

Walters BB, Ronnback P, Koraas J, et al. 2008. Ethnobiology, socio-economic and adaptive management of mangrove: a review. Aquatic Botany 89: 220-236.

Wang Y, Nil N. 2000. Changes in chlorophyll, ribulose biphosphate carboxylase-oxygenase, glycine betaine content, photosynthesis and transpiration in Amaranthus tricolor leaves during salt stress. The Journal of Horticultural Science and Biotechnology 75: 623-627.

Wei L, Lockington DA, Poh SC, Gasparon M, Lovelock CE. 2013. Water use patterns of estuarine vegetation in a tidal creek system. Oecologia 172: 485-494.

Yakir D, Yechielie Y. 1995. Plant invasion of newly exposed hypersaline Dead Sea shores. Nature 374: 803-805.

Ye Y, Tam NFY, Lu CY, Wong YS. 2005. Effects of salinity on germination, seedling growth and physiology of three salt-secreting mangrove species. Aquatic Botany 83: 193-205.

Zhu JK. 2002. Salt and drought stress signal transduction in plants. Annual Review of Plant Biology 53: 247-273. 